\title{
ADDIEM - Um Processo para Criação de Cursos MOOC
} ADDIEM - Process for Creating MOOC Courses

\section{Vanessa Battestin ${ }^{1 *}$}

Pollyanna da Silva Santos ${ }^{1}$

${ }^{1}$ Instituto Federal de Educação, Ciência e Tecnologia do Espírito Santo - Rua Barão de Mauá, 30, Vitória - ES - Brasil.

*vanessa@ifes.edu.br

\section{Resumo}

Este artigo apresenta a proposta de um processo de criação de cursos MOOC, batizado como ADDIEM, que foi concebido a partir do modelo ADDIE e customizado para as especificidades dos MOOC e concepções de uma instituição pública. Para cada etapa do processo, foram definidos seus objetivos e artefatos gerados, bem como foram criados os modelos de documentos que servem de suporte. O processo e seus modelos de documento foram avaliados por uma comissão e por profissionais da área de ensino. Após ajustes, o ADDIEM foi, então, validado e, posteriormente, avaliado por professores que o utilizaram para elaboração de cursos. Resultados apontam que o modelo foi bem aceito e que efetivamente apoia os professores no processo de construção. Apesar de concebido no contexto de uma instituição, pode ser utilizado ou adaptado para outras.

Palavras-chave: MOOC. ADDIEM. Modelo para criação de cursos.

\section{(c) (i)}

Recebido 25/10/2021

Aceito $\quad 17 / 01 / 2022$

Publicado 26/01/2022
COMO CITAR ESTE ARTIGO

ABNT: BATTESTIN, V; SANTOS, P. S. ADDIEM - Um Processo para Criação de Cursos MOOC. EaD em Foco, v. 12, n. 1, e1648, 2022. https://doi.org/10.18264/eadf.v12i1.1648 


\section{ADDIEM - Process for Creating MOOC Courses}

\section{Abstract}

This article presents a model for the creation of MOOC courses, based on the ADDIE model, which adapts to the specificities of two MOOCs and the institution's conceptions, obtained or the ADDIEM model. In each stage, the objectives and artifacts generated are presented, as well as the models that support them. The process and its document models were evaluated by a commission and by teaching professionals. After adjustments, ADDIEM was then validated, subsequently, evaluated by teachers who used it to prepare courses. Results indicate that the model was well accepted and that it effectively supports teachers in the construction process. Although designed in the context of a institution, it can be used or adapted for other ones.

Keywords: MOOC. ADDIEM. Course creation model.

\section{Introdução}

As pessoas, cada vez mais, precisam adquirir novos conhecimentos e habilidades para acompanhar o mundo atual, em que temos uma presença muito forte da tecnologia e em que as mudanças ocorrem muito rapidamente. Uma alternativa que se expandiu sobremaneira nos últimos anos foi a educação a distância (EaD), cujos cursos são mais flexíveis em termos de tempo (horários de realização) e espaço (locais de estudo). Segundo o Censo da EaD de 2018 (ABED, 2019), os cursos EaD no país vêm aumentando ano após ano, mas desde 2016 este crescimento tem sido vertiginoso, tendo passado de 3.734 .887 matrículas em 2016, para 9.374.647 em 2018.

Porém, por mais que um curso a distância seja muito mais flexível que um curso presencial, ele ainda possui algumas características que podem dificultar o acesso ao conhecimento. Por exemplo, em geral, possuem turmas com número limitado de alunos, possuem prazos bem definidos de início, fim e de entrega de atividades e, em muitos casos, há obrigatoriedade de encontros presenciais. Essas dificuldades se mostraram presentes no Instituto Federal de Educação, Ciência e Tecnologia do Espírito Santo (Ifes), especialmente quando era necessário realizar formações das equipes, bem como oferecer cursos complementares a alunos.

Assim, nos últimos anos, tem aumentado muito a oferta dos chamados MOOCs ou Massive Open Online Courses (no Português: Cursos On-line, Abertos e Massivos). Ainda que não haja uma definição consensual, um MOOC é, em geral, um curso aberto (sem pré-requisitos para participação), on-line (sem atividades presenciais), e massivo (oferecido para um grande número de alunos). Assim, podem ser vistos como uma grande forma de inclusão, uma vez que são gratuitos, podem ser cursados por qualquer pessoa, de qualquer lugar e no seu tempo, e que podem usar uma enorme gama de ferramentas e recursos, permitindo acesso, inclusive, a alunos com algum tipo de deficiência.

MOOCs podem ser ofertados visando à atualização contínua ao longo da vida, aprendizado de novas ferramentas e tecnologias, capacitação de equipes, preparatórios para exames e concursos, nivelamentos de disciplinas, para tratar de conteúdos específicos, para ensinar uma nova língua, para adquirir uma nova competência, entre outros.

Dadas às suas vantagens e características, diversas instituições ao redor do mundo têm criado seus provedores de MOOCs. Considerando a crescente oferta, torna-se importante definir um modelo ou pro- 
cesso de construção de cursos $\mathrm{MOOC}$, e que este seja prático para o docente ou instrutor, uma vez que modelos muito burocráticos podem desestimular, mas que também seja um caminho para a construção de cursos de qualidade.

Desta forma, o objetivo deste trabalho foi apresentar um modelo de criação de cursos MOOC, definido com base no modelo ADDIE de criação de cursos a distância e nas características de MOOCs adotadas na instituição, chegando ao ADDIEM, acrônimo de Analysis, Design, Development, Implementation e Evaluation in MOOCs. O modelo elaborado foi para uma instituição de ensino pública específica, mas pode, também, ser utilizado e/ou adaptado por outras instituições.

\section{Referencial Teórico}

\subsection{MOOC}

Os cursos on-line, abertos, massivos ou MOOCs, do inglês Massive Open Online Courses, são cursos on-line diferentes dos cursos a distância mais tradicionais. Suas principais características são serem abertos e massivos, ou seja, disponíveis para qualquer um que tenha acesso à internet, e serem disponibilizados em larga escala. Em geral, têm curta duração e estão em várias plataformas no mundo (MATTAR, 2013).

Segundo Dal Forno e Knoll (2013, p.178), o termo MOOC foi utilizado pela primeira vez no ano de 2008, por Dave Cormier, fazendo referência a George Siemens e Stephen Downes, em que, na Universidade de Manitoba, no Canadá, disponibilizaram um curso totalmente on-line sobre Conectivismo e Conhecimento conjuntivo, contanto com 2.200 matrículas do mundo todo. O tema Conectivismo abordado no curso, inclusive, tem sido considerado por diversos autores como uma abordagem pedagógica para os MOOCs, ainda que muitos não o considerem uma nova teoria de aprendizagem (MATTAR, 2013).

Siemens (2004, p.9) apresenta o Conectivismo como um modelo "em que a aprendizagem não é mais uma atividade interna e individual", mas que se dá também por meio de conexões com outras pessoas e outros ambientes. Segundo Mattar (2013, p.29), trata-se de uma teoria mais adequada para a era digital, sendo os MOOCs uma das tentativas de ampliar essa teoria para larga escala.

Nos últimos anos, diversos provedores de MOOCs têm sido lançados em todo o mundo, seja por instituições de ensino públicas ou privadas, empresas, instituições sem fins lucrativos, etc. Exemplos ao redor do mundo são Udacity, edX, Udemy, Khan Academy e Coursera (EUA), Open2study (Austrália), Alison (Irlanda), Miríada (Espanha), Future Learn (Reino Unido), Fun (França), Iversity (Alemanha). No Brasil, alguns exemplos são Veduca (SP), TIMTec (SP), Lúmina (UFRS), Poca (UFSCar), Cursos gratuitos e abertos (IFRS), Plataforma de Cursos Abertos (Ifes), Eskada (Uema).

Esses provedores, muitas vezes, diferem quanto às características dos MOOCs. Uma das características é a interatividade entre as pessoas, em uma perspectiva de aprendizagem colaborativa, surgindo categorizações como a de Andrade (2016, p.105), dos Connectivism-based MOOCs (cMOOC), baseados na interação entre os participantes e dos eXtended MOOCS (XMOOC), baseados na transmissão de conteúdos. Ribeiro e Catapan (2018, p.57) trazem diversas outras classificações.

Outra característica que pode variar é a presença de um professor ou tutor para fazer a mediação com os alunos, sanando dúvidas e acompanhando o processo de aprendizagem. Na maioria dos provedores, os cursos são realizados por autoestudo. O fato de serem gratuitos ou pagos ou terem a certificação gratuita ou paga também varia. 
No contexto deste trabalho, consideram-se MOOCs cursos on-line, de curta duração, abertos ao grande público, sem processos seletivos, gratuitos, com certificação automática - após atingir os critérios estabelecidos, e que não possuem tutoria, sendo de autoestudo. A Figura 1 exibe um resumo das características.

Figura 1: Principais características dos cursos MOOC

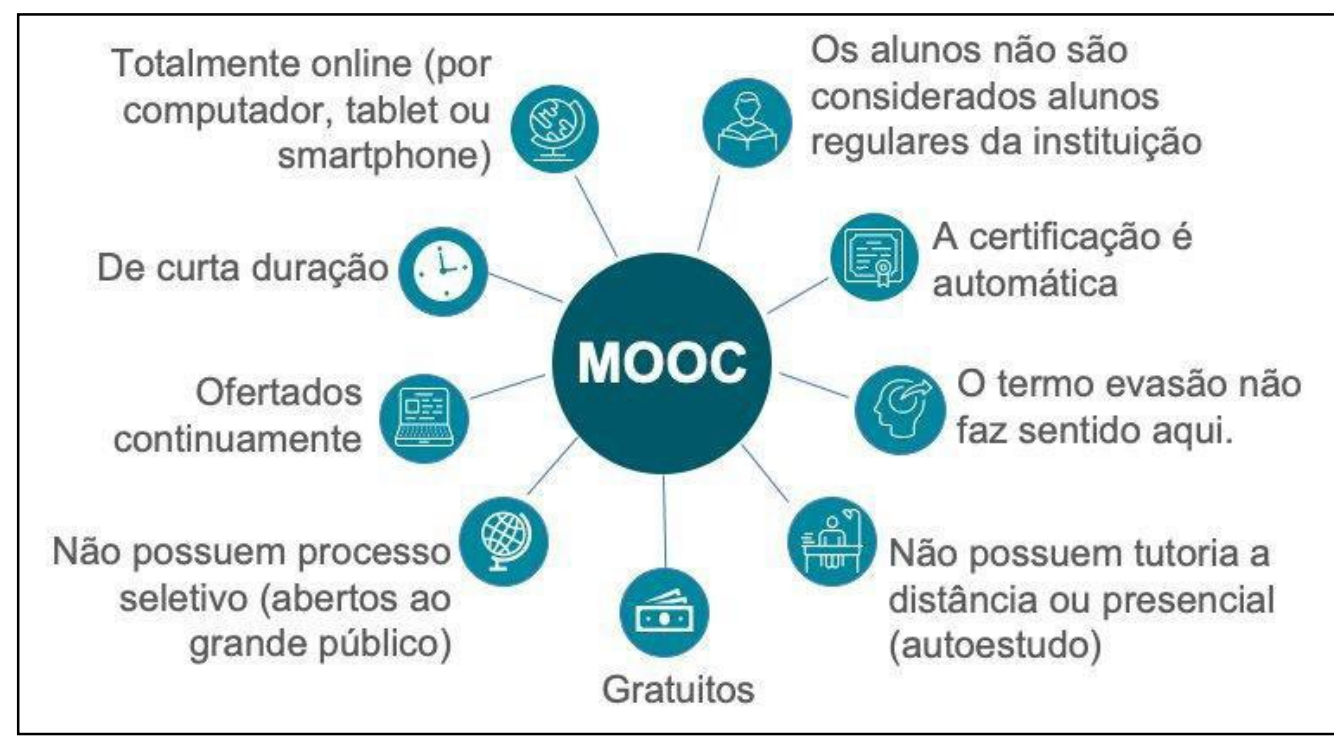

Fonte: Autoras (2019).

Com relação à construção de $\mathrm{MOOC}$, propostas de modelos têm surgido na literatura. Uma delas é a de Costa, Santos, Moura, Silva e Viana (2015, p.329, 332), que apresenta guias para desenhos de MOOCs em três níveis e que expõe uma interação obrigatória nos fóruns específicos, o que, segundo Mattar (2015, p.30), leva a um aspecto distinto à essência dos MOOCs. Fassbinder, Barbosa e Magoulas (2017, p.03) apresentam uma pesquisa com alguns padrões para produção de MOOCs, dando destaque à aprendizagem invertida, que permite ao professor autonomia e ao aluno autogestão do conhecimento. Entretanto, não há detalhamento dos padrões ou descrição de suas etapas.

Murthy, Warriem, Sahasrabudhe, lyerr (2018, p.02) descrevem o Learner Centric MOOC (LCM) contendo quatro elementos: "diálogos de aprendizagem; atividades de aprender fazendo; interação da experiência de aprendizagem e trajetórias de extensão de aprendizagem e dinâmica de orquestração". Trata-se de uma interessante abordagem centrada no aluno e com ênfase nas atividades; entretanto, não descreve outros aspectos para o design de um curso. Seidametova (2018, p.247) apresenta os quasi MOOC e as quatro etapas para sua produção: preparatória, organizacional, gestão e lançamento. O modelo tem ênfase em templates que facilitam a criação pelo professor, mas possuem certo engessamento que pode tirar sua autonomia, além de não possuir orientações de acompanhamento e avaliação da produção do curso. Por fim, Yong e Li (2018, p.651-653) apresentam uma experiência na produção de quatro cursos MOOC, gerando um modelo com quatro fases e subfases. O processo parece bem completo, mas exige uma equipe maior e possui uma complexidade de produção que pode inviabilizar a construções de MOOCs em muitas instituições, especialmente com equipes reduzidas.

Com relação à avaliação de MOOCs, algumas possibilidades são abordadas na literatura. Destacamos a proposta de Souza, Morgado e Marinho (2019, p.04), que trata, entre outras coisas, da "importância da análise por especialista" e do "teste empírico".

Os modelos pesquisados, ainda que trouxessem boas iniciativas para seus contextos, não atendiam plenamente ao nosso propósito, uma vez que ou não estavam alinhados às nossas concepções de MOOC; ou eram complexos para produção pelo professor, sem uma grande equipe de apoio; ou não cobriam 
todas as etapas necessárias para construção de um MOOC, como a de avaliação; ou não traziam uma definição clara e modelos que permitissem a replicação e/ou adaptação em outros contextos. Entretanto, eles nos auxiliaram no processo de concepção do nosso processo.

\subsection{Modelo ADDIE}

Na literatura, um modelo que tem sido bastante adotado por muitas instituições para construção de cursos a distância é o ADDIE, acrônimo de Analysis, Desing, Development, Implamentation and Evaluation, que no português pode ser traduzido como Análise, Desenho (ou Projeto), Desenvolvimento, Implementação e Avaliação. Filatro (2008) pontua que nesse modelo há duas divisões: a concepção, onde está inserida a análise, o design e o desenvolvimento, e a execução, onde está a implementação e a avaliação.

Na fase da Análise, o problema é identificado a partir da avaliação do contexto e do público-alvo para qual o curso será produzido. Nesse momento, são definidos objetivos e características relevantes, bem como recursos disponíveis, prazos, etc. Aqui é onde se terá uma visão geral a respeito do curso.

No Desenho, são mapeados os conteúdos a serem trabalhados. Há uma estruturação das metas de aprendizado e é o momento em que se deve detalhar cada módulo e que recursos estarão presentes (vídeos, links, livros, textos, etc.).

No Desenvolvimento, devem ser produzidos todos os materiais projetados (materiais textuais, videoaulas, atividades, etc.). Essa fase é uma das mais importantes e deverá estar interligada aos objetivos de aprendizagem do curso.

A Implementação compreende a configuração do ambiente onde serão disponibilizados os materiais produzidos na etapa anterior. Para Filatro (2008), é importante ter apoio de um técnico no momento da estruturação da plataforma.

Por fim, a última etapa é a Avaliação, em que o curso é avaliado por possíveis alunos e especialistas no assunto. Aqui são encontrados erros e sinalizados pontos de melhorias tanto na parte técnica quanto na pedagógica.

O modelo ADDIE traz etapas em que pudemos nos basear e que foram fundamentais para estruturar as etapas do modelo para MOOCs e para nossa realidade - o ADDIEM.

\section{Metodologia}

Este trabalho, quanto à sua natureza, caracteriza-se como uma pesquisa aplicada, que, segundo Schwartzman (1979, p.1), é "aquela que tem um resultado prático visível em termos econômicos ou de outra utilidade que não seja o próprio conhecimento". O local de pesquisa em que o trabalho foi aplicado é uma instituição pública federal de ensino.

Neste trabalho, inicialmente foi realizada uma revisão de literatura sobre MOOCs e seus modelos de construção, bem como sobre o modelo ADDIE, nas bases Google Schollar, Portal de Periódicos da Capes, Biblioteca Virtual Pearson, Repositório da Universidade Aberta e portal arxiv.org da Cornell University. Foram catalogados 25 trabalhos, dos quais oito mais relevantes para este trabalho foram analisados em maior profundidade.

Em paralelo, uma das autoras deste trabalho presidiu uma comissão que visava implantar os MOOCs em sua instituição, local da pesquisa, composta por especialistas de diferentes setores e funções: profissionais de design educacional, tecnologia de informação, secretaria acadêmica, gestão e professores. 
Nesta comissão, foi definida a concepção de MOOC que seria adotada, dadas as características da instituição e seus processos de EaD, cujo resumo foi apresentado na seção anterior, bem como foram criados os regulamentos necessários para o funcionamento dos MOOCs e o provedor institucional.

Com base na análise dos trabalhos levantados e nas definições institucionais, elaboramos um processo de criação de MOOCs - o modelo ADDIEM, que será explicado na seção seguinte. Nesta construção, foram realizadas definições para cada fase correspondente do modelo ADDIE, focando especialmente nos objetivos e nos produtos gerados. Ao final deste momento, foi elaborado um documento com uma ilustração que resume o modelo, bem como uma explicação sucinta do mesmo, com o objetivo de auxiliar os professores que venham a utilizá-lo (BATTESTIN E SANTOS, 2019). Uma vez realizadas essas definições, foram elaborados os modelos de documentos referentes a cada fase do ADDIEM. A comissão institucional, além de participar na elaboração dos modelos de documentos e na validação do processo como um todo, construiu, em seguida, um processo formal para tramitação de projetos de MOOCs na instituição (IFES, 2019).

O modelo ADDIEM passou, então, a ser utilizado para criação de MOOCs na instituição, o que tem ocorrido desde meados de 2019. É importante destacar que os primeiros professores a construírem seus MOOCs o fizeram com o modelo ADDIEM parcialmente construído e sem ainda alguns modelos de documentos.

A avaliação do modelo ADDIEM, incluindo seus modelos de documento, foi realizada inicialmente pela comissão institucional e por outros especialistas. O modelo também foi apresentado aos gestores da instituição e a outros profissionais, que puderam também dar sua contribuição. Com base nos feedbacks fornecidos, foram realizados ajustes. Posteriormente, professores que construíram seus MOOCs foram convidados a responder a uma breve pesquisa sobre o modelo adotado, que foi analisada quanti-qualitativamente. 26 responderam à pesquisa e uma discussão sobre a avaliação consta na seção 5.

\section{O modelo ADDIEM}

Uma vez que o modelo ADDIE é internacionalmente conhecido na construção de cursos a distância, optou-se por utilizá-lo como ponto de partida para definir um modelo para os MOOCs, porém fazendo as devidas adequações e construções tanto ao que é específico aos MOOCs como às características da instituição. Além disso, foram elaborados os modelos de documentos necessários nas etapas. O ADDIEM é apresentado na Figura 2.

Figura 2: Modelo ADDIEM

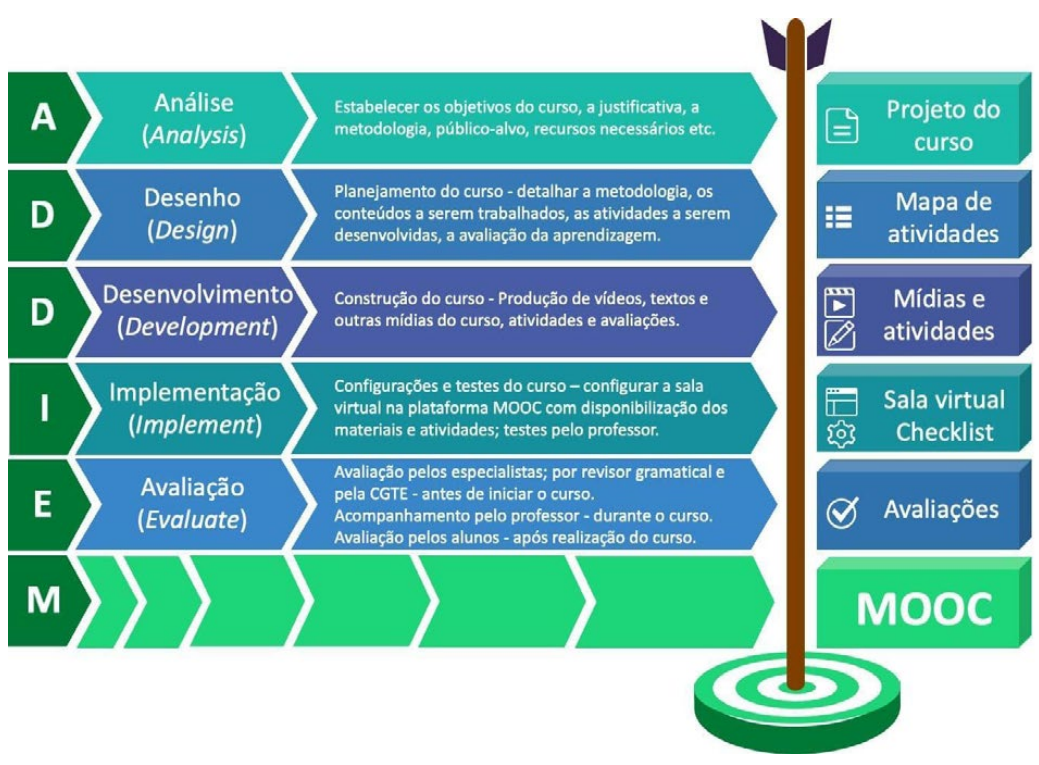


A fase de Análise (Analysis) é o momento de estabelecer os objetivos do curso, a justificativa, a metodologia, o público-alvo, o idioma, os recursos necessários, a equipe, as formas de fomento, os pré-requisitos, os resultados esperados, a avaliação da aprendizagem, entre outros. É nesta fase que se elaborará o projeto do curso (Figura 3).

Figura 3: Partes do Modelo de Projeto de MOOCs

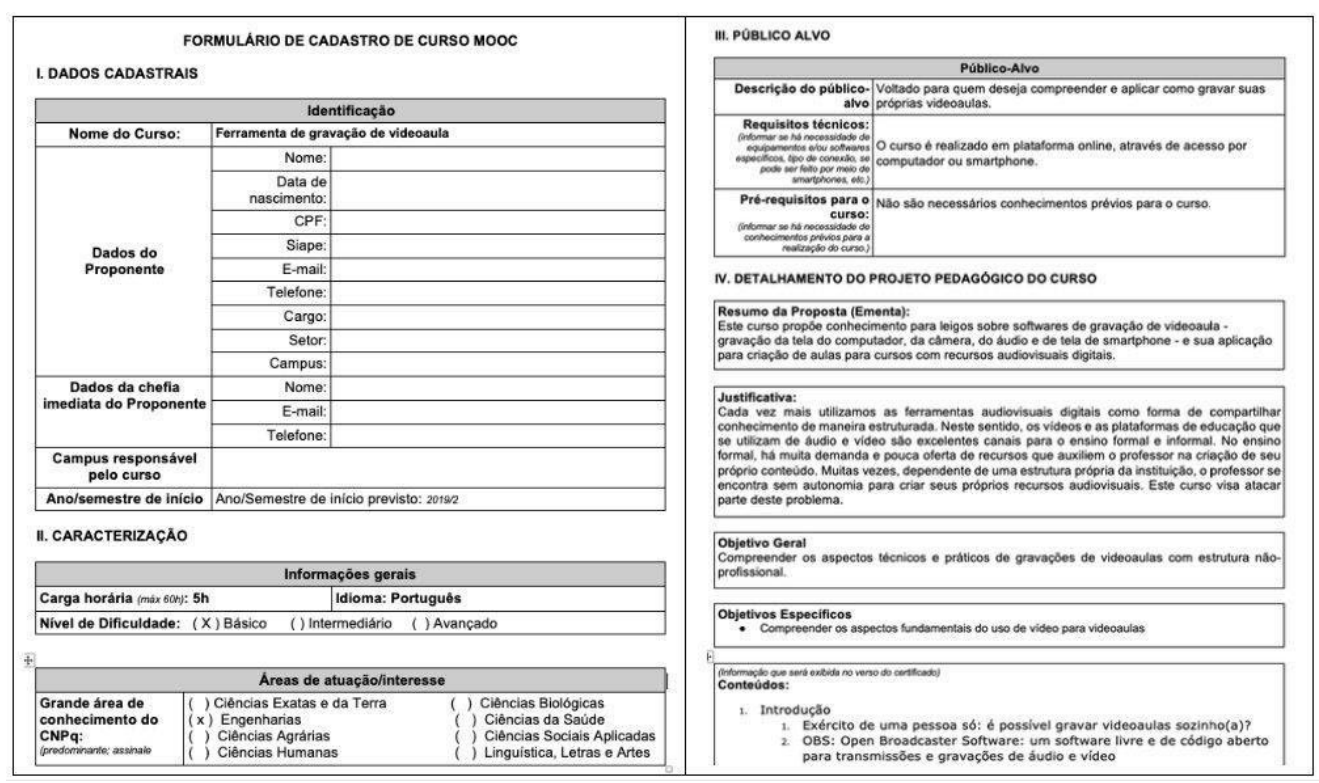

Fonte: Elaborado pela comissão para criação de cursos MOOC do IFES (2019).

A Figura 3 exibe partes do modelo de projeto de MOOC definido. Para exemplificar, ele foi parcialmente preenchido para um curso. O modelo completo encontra-se em https://bit.ly/modelProjCurso.

Em seguida, vem a fase de Desenho ou Projeto (Design), que tem como foco principal o planejamento do curso. Nesta fase, é momento de detalhar a metodologia, os conteúdos a serem trabalhados, as atividades a serem desenvolvidas e a avaliação da aprendizagem. Neste momento, será elaborado o mapa de atividades. A Figura 4 exibe o modelo de mapa de atividades, parcialmente preenchido para o curso do projeto exibido anteriormente.

Figura 4: Modelo de Mapa de Atividades para MOOCs

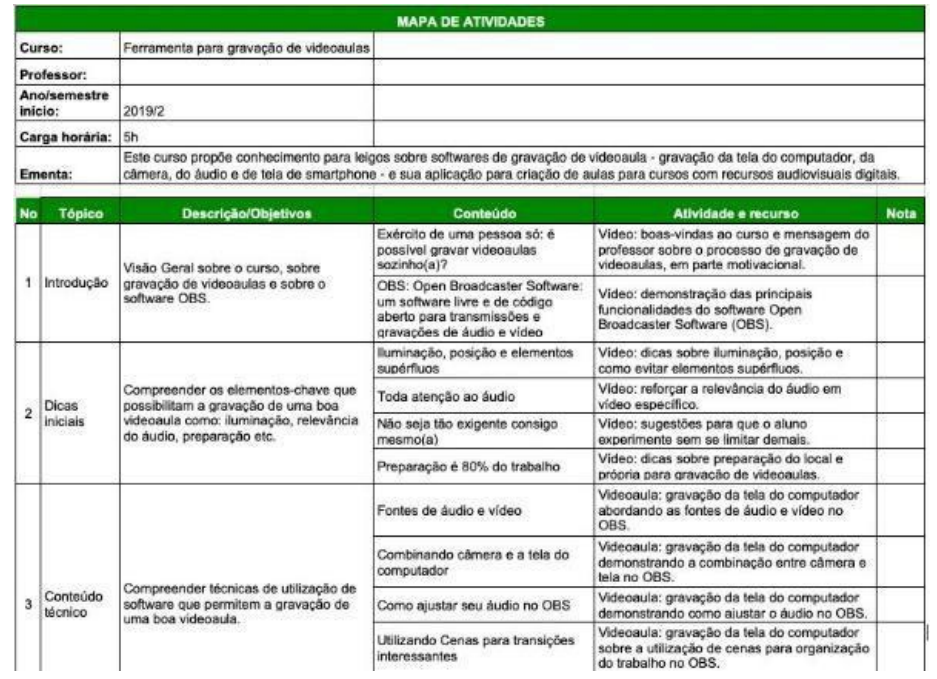

Fonte: Elaborado pela comissão para criação de cursos MOOC do IFES (2019). 
Como se pode observar, o modelo de mapa de atividades proposto aqui é mais enxuto do que os modelos que algumas instituições utilizam para o planejamento dos cursos a distância. Essa simplificação se deu por dois motivos. Primeiro, devido às resistências há anos por parte dos professores em preencher modelos muito detalhados. Segundo, porque objetivamos que o mapa possa dar uma visão geral do curso ao professor, inclusive em termos estruturais. Assim, por exemplo, os tópicos do mapa se transformarão em tópicos na sala virtual, bem como os conteúdos definidos serão os trabalhados em cada tópico. O modelo do mapa de atividades está disponível em https://bit.ly/MapaAtividades.

Planejado o curso, é momento de produzi-lo. Na fase de Desenvolvimento (Development), é realizada a produção de videoaulas, textos e as outras mídias que serão utilizadas no curso. Também é momento de criar as atividades e avaliações. Esta é a etapa que costuma consumir mais tempo na produção de um MOOC.

A Figura 5 exibe parte da sala virtual de um MOOC, após o professor ter inserido os conteúdos criados. Como se pode ver, ao comparar com a Figura 4, há uma correlação direta entre o que está na sala virtual e o que foi planejado no mapa de atividades.

Figura 5: Parte da sala virtual de um MOOC

\begin{tabular}{l} 
Ferramenta para Gravação \\
de Videoaulas \\
D Emblemas \\
$\square$ Notricipantes \\
$\square$ Área do curso \\
$\square$ Conteúdos \\
$\square$ Material complementar \\
$\square$ Atividade avaliativa \\
$\square$ Certificado e conclusão \\
Painel \\
\hline
\end{tabular}

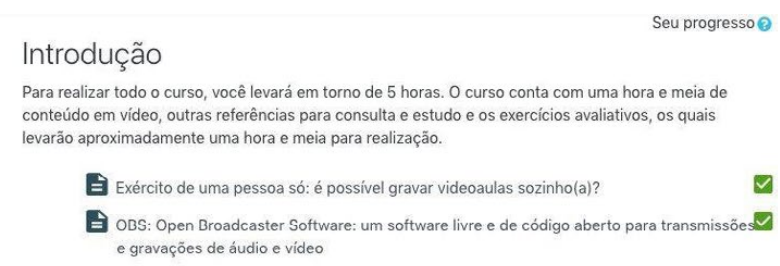

Dicas iniciais

Antes de seguirmos para os aspectos técnicos do software OBS, gostaria de deixar algumas dicas para nortear seu estudo neste curso. Acompanhe abaixo.

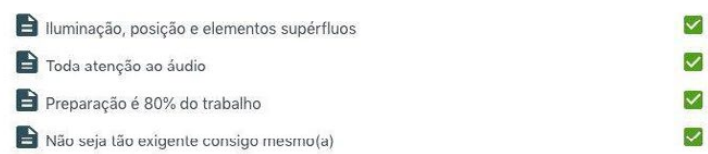

Conteúdo técnico

Nesta parte entraremos nos aspectos dos softwares necessários para gravação de suas aulas, bem como seus aspectos mais técnicos, focados no uso de cada software.

Fonte: Elaborado pelas autoras, com base em IFES, 2019.

Na Implementação (Implement), são realizadas as configurações da sala virtual no provedor de MOOCs, onde materiais e atividades são inseridos. Na instituição dessa pesquisa, a plataforma utilizada pelo provedor de MOOCs é o Moodle. Ainda nesta fase, são realizados testes pelo professor, inclusive para verificar se os alunos têm acesso aos conteúdos e atividades da forma desejada. Por fim, o professor realiza um checklist, utilizando o modelo definido, disponível em https://bit.ly/checklistMooc.

A Figura 6 apresenta parte dele.

Figura 6: Parte do checklist do professor

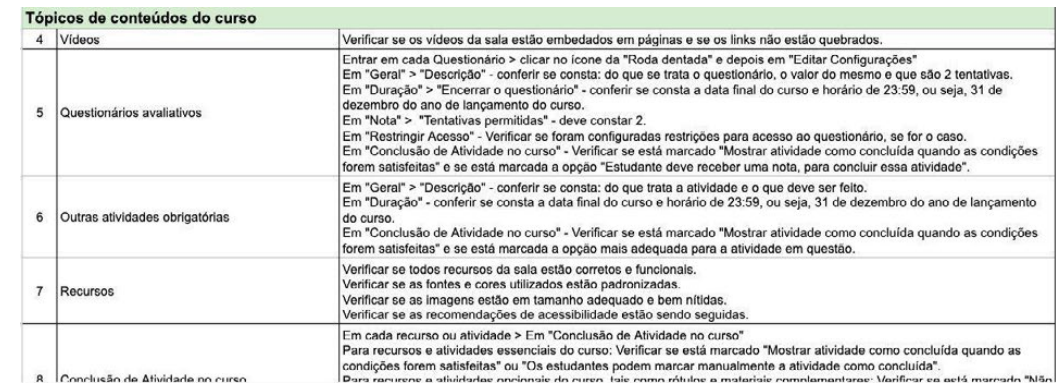

Fonte: Elaborado pela comissão para criação de cursos MOOC do IFES (2019). 
Neste momento, a primeira versão do curso estará finalizada e se dará início à fase de Avaliação (Evaluate). Especialistas na área e, se desejado, pessoas com o perfil do público-alvo são indicadas para avaliar o curso. Elas farão o curso como alunos e preencherão um formulário de avaliação, indicando possíveis melhorias. A Figura 7 apresenta parte do formulário de avaliação. O modelo encontra-se em https:// bit.ly/avaliacaoEspec.

Figura 7: Parte do formulário de avaliação pelo especialista

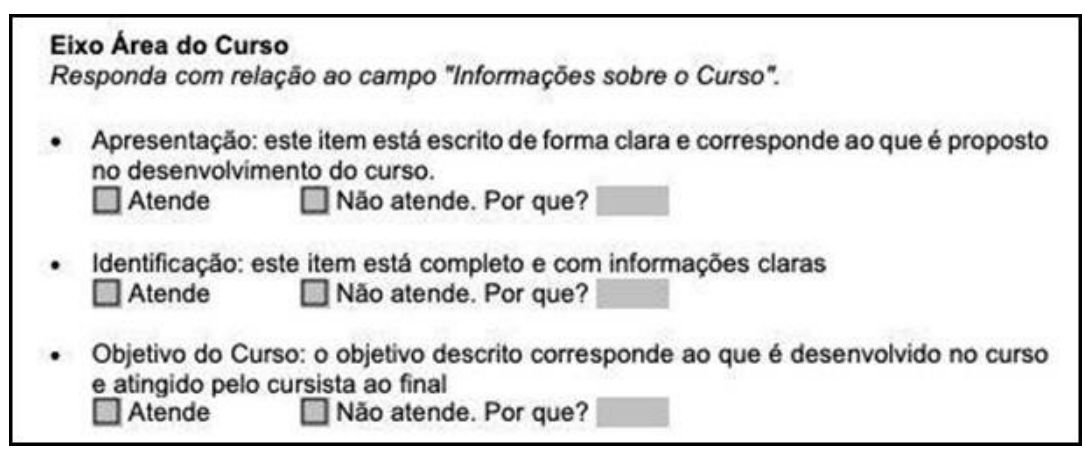

Fonte: Elaborado pela comissão para criação de cursos MOOC do IFES (2019).

De posse das avaliações dos especialistas, o professor/instrutor realiza os ajustes necessários e envia a um revisor de Português (ou língua do curso).

Em seguida, é realizada uma avaliação técnica por equipe especializada em tecnologia e design educacional. Após esta, os últimos ajustes são realizados, se necessário. O modelo de avaliação técnica está disponível em https://bit.ly/avaliacaoTecnica.

É importante lembrar que o presente trabalho trata de uma instituição pública e que o modelo de processo foi elaborado pensando especialmente em cursos ofertados dentro da carga horária regular de trabalho dos envolvidos. Entretanto, havendo outros recursos, como de parcerias, projetos governamentais ou no caso de instituições privadas, pode-se contratar equipe técnica para revisão de línguas e por especialistas.

Após esta primeira etapa da avaliação, o MOOC está pronto para ir ao ar. Entretanto, esta fase permanece com outras duas atividades.

No primeiro semestre do curso, especialmente, o professor/instrutor realiza o acompanhamento do curso, verificando postagens em fóruns, atividades realizadas pelos alunos e os chamados advindos do sistema de suporte, visando identificar possíveis necessidades de ajustes e melhorias. É válido ressaltar que o sistema de suporte filtra e atende a maior parte dos casos, geralmente relacionados a questões de acesso ou dúvidas gerais. As específicas que são encaminhadas ao professor são relativas a problemas quanto ao conteúdo ou às atividades do curso. Lembrando que os MOOC aqui tratados não possuem mediação (tutoria); assim, eles precisam ser construídos de forma que o aluno consiga realizá-los de forma autônoma.

Outro importante instrumento de análise são as avaliações preenchidas pelos alunos assim que finalizam o curso. Este instrumento ajuda o professor a identificar melhor com base na ótica dos alunos. As perguntas disponíveis nesse formulário podem ser visualizadas em https://bit.ly/avaliacaoAluno.

Por fim, é importante destacar que, além de ter disponibilizado o modelo ADDIEM e seus modelos de documentos, em 2020, foi elaborado pelas autoras um MOOC para orientar professores quanto ao processo de construção. A Figura 8 mostra uma parte do curso. 
Figura 8: Parte da sala virtual do curso "Como criar um MOOC"

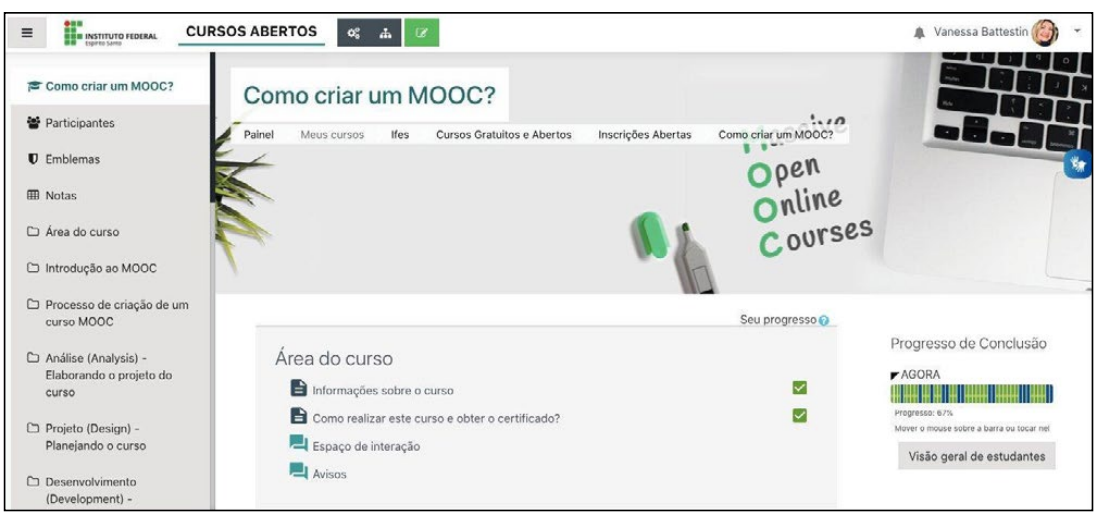

Fonte: Elaborado pela comissão para criação de cursos MOOC do IFES (2019).

\section{Avaliação do modelo ADDIEM}

\subsection{Avaliação pela comissão MOOC e outros profissionais}

No decorrer do processo de elaboração do modelo ADDIEM, tanto o modelo do processo em si como seus modelos de documento foram avaliados pelo grupo de especialistas da comissão de MOOCs da instituição e, também, por profissionais externos à comissão, da área de ensino. O modelo também foi apresentado aos gestores e outros profissionais da instituição, que puderam colaborar. Com base nos feedbacks fornecidos, ajustes foram realizados. As necessidades de ajustes advindas dos feedbacks se resumiram em criação de novos campos em modelos de documento e adequação de campos existentes.

A avaliação do modelo ADDIEM também foi realizada por professores de MOOCs, que o estavam utilizando para criação de seus cursos simultaneamente à construção do processo. Os principais feedbacks dos professores foram quanto à necessidade de criação de novos modelos de documento. Um deles foi o checklist, pelo professor da fase de Implementação, que não existia na versão inicial, pois os professores queriam ter uma maneira rápida e prática de verificar se seu curso estava configurado corretamente, antes de enviá-lo para avaliação. Os outros modelos de documento sugeridos foram em decorrência do processo formal da instituição, que passou a necessitar, por exemplo, de alguns termos de anuência. O processo formal também passou a exigir, a partir de 2020, que os proponentes de MOOCs apresentassem o certificado do curso "Como criar um MOOC?", ou seja, eles deveriam conhecer o processo antes de propor um novo curso.

É importante ressaltar que os ajustes necessários foram realizados e novos modelos criados, de forma que o processo e os modelos de documento aqui apresentados neste artigo já são os validados.

\subsection{Avaliação pelos professores}

Periodicamente, solicitamos aos professores de MOOCs da instituição que preencham uma pesquisa web sobre o processo de criação definido e utilizado - o ADDIEM. Até o momento, tivemos a resposta de 26 professores. É válido reforçar que alguns responderam logo no início, quando o processo ainda estava em construção e a produção dos cursos se deu de forma concomitante. Outros responderam após o processo estar concluído, e outros, ainda, após ter realizado o curso "Como criar um MOOC?".

Dos 26 professores, 20 (70\%) responderam que nunca haviam produzido um MOOC e seis já haviam produzido em outras plataformas. 13 professores (50\%) realizaram o curso "Como criar um MOOC?". Os demais produziram seus MOOCs antes de ele ser lançado. 
Quando perguntados sobre os aspectos mais relevantes na construção de seu MOOC, quanto ao modelo ADDIEM e seus modelos de documento, os mais destacados foram: "O mapa de atividades auxiliou o meu planejamento" (77\%); “O processo me auxiliou a compreender e seguir as etapas necessárias” (73\%); "As avaliações realizadas foram importantes para melhoria do meu curso" (73\%); "O processo é de fácil compreensão e está bem explicado" (73\%); "O projeto do curso direcionou os meus primeiros passos no planejamento" (69\%);. Como se pode ver, foram destacados aspectos fundamentais no modelo, com ênfase quanto às atividades e modelos de planejamento e avaliação, que remetem à qualidade do curso por eles elaborado. Embora a maioria dos professores tenha citado a importância do uso do mapa de atividades, uma professora, porém, citou não gostar de utilizá-lo: “Como considero a criação de um curso algo orgânico e criativo, não consigo me prender ao mapa de atividades para planejá-lo. Acho que o mapa engessa e tolhe minha criatividade". É válido destacar que, apesar de incentivado, o mapa de atividades é opcional no ADDIEM.

Quando perguntado se consideravam que, seguindo o processo definido, o professor era capaz de projetar um curso MOOC do começo ao fim, tivemos 24 professores (92\%) que responderam "sim", dois responderam "parcialmente" e nenhum respondeu "não". Um destaque importante aqui é que as duas professoras que responderam "parcialmente" criaram seus MOOC logo no início, antes do processo e de seus modelos de documento terem sido concluídos. Deste modo, temos que todos $(100 \%)$ os professores que seguiram o processo finalizado consideram que o mesmo atente totalmente.

Por fim, deixamos um espaço para que o professor pudesse falar livremente, fazer sugestões ou mesmo citar a diferença entre construir um MOOC antes e depois do processo finalizado, para os que estiveram nessa situação. Nem todos responderam, mas dentre os respondentes, os pontos mais destacados foram: a importância do processo e dos modelos de documentos criados (citado por 14 professores). Um professor reforçou a importância para o planejamento sistematizado: “O processo me ajudou a compreender as fases de criação e desenvolvimento de um curso e a necessidade de planejamento do curso de forma mais sistematizada". Outra professora citou o auxílio para construção de mídias: "O processo finalizado me auxiliou a enxergar com clareza as etapas de construção de um curso MOOC e os documentos que foram definidos nessa última etapa foram primordiais para direcionar a elaboração das mídias para o meu curso". Uma professora destacou que o modelo orienta, mas não tolhe: "O modelo nos dá o como fazer, ajudando a criação e propagação de qualquer metodologia de ensino". Quatro professores também citaram a importância do curso "Como criar um MOOC?" como orientador do processo de construção. Outros professores reforçaram a avaliação e a busca da qualidade: "A importância do Cheklist e da avaliação dos especialistas auxiliam em muito na melhoria do processo de construção de um mooc"; "Ficou mais clara a exigência de qualidade para o curso e os passos necessários para atender a essa qualidade exigida. Com o processo claro todos ganham". Duas professoras que fizeram seus cursos enquanto o processo ainda não estava concluído citaram que foram necessários esclarecimentos adicionais com a equipe técnica. Entretanto, isso não foi citado pelos demais professores.

\subsection{Avaliação dos participantes do curso "Como criar um MOOC?"}

No momento desta análise, 219 pessoas haviam finalizado o curso "Como criar um MOOC?" e, assim, realizado sua avaliação. 75 (34\%) estavam cursando um MOOC pela primeira vez, sendo que 16 (7\%) nunca tinham feito um curso a distância. 49 (22\%) eram servidores, 64 (29\%) alunos da instituição, e 106 (48\%) eram público externo. A maioria estuda e trabalha $(131=60 \%)$, possui pós-graduação $(147=67 \%)$ e lida bem com tecnologias $(200=91 \%)$. Entretanto, seis citaram mal conseguir realizar atividades sem auxílio. Sobre o porquê fez o curso, 128 (58\%) citaram que era um assunto que precisavam aprender.

Na pergunta "Como você avalia este curso?", 156 responderam "Muito bom", 53 responderam "Bom", sete responderam "Regular" e três responderam "Ruim" ou "Muito Ruim". Desta forma, temos 209 (95\%) que consideram o curso muito bom ou bom - o que é bastante significativo. Quanto às expectativas no 
curso, 212 (97\%) responderam que o curso "atendeu" ou "superou as expectativas", sendo que destes, 54 (25\%) responderam que "superou", e sete pessoas (3\%) responderam que o curso não atendeu às expectativas. Por fim, ao perguntarmos que nota daria ao curso, de 1 a 10, a nota 10 foi predominante (138= $63 \%)$, sendo que a nota média foi 9,3.

\section{Conclusão}

O objetivo deste artigo foi apresentar o processo desenvolvido para elaboração de cursos MOOC do Instituto Federal do Espírito Santo - Ifes, o modelo ADDIEM, bem como os modelos de documento necessários em suas fases. O processo e os modelos foram avaliados e os ajustes foram realizados, para se chegar ao resultado final aqui apresentado.

Tanto pela vivência com o processo, pela avaliação dos pares e outros especialistas, bem como pelos feedbacks dos professores, percebemos que o ADDIEM tem atendido bem no auxílio à construção de MOOCs e não tem havido resistência ou grande dificuldade pelos professores, especialmente após o processo estar completamente definido. Além disso, o curso "Como criar um MOOC?" tem sido muito importante para auxiliar no entendimento de cada fase do processo, o que foi evidenciado na sua excelente avaliação.

É importante novamente ressaltar que as definições aqui exibidas estão dentro do contexto de uma instituição pública que considera MOOCs como cursos on-line, de curta duração, abertos, gratuitos e sem tutoria. Entretanto, o processo e os modelos elaborados são gerais o suficiente para serem utilizados ou adaptados para uso em outras instituições.

\section{Biodados}

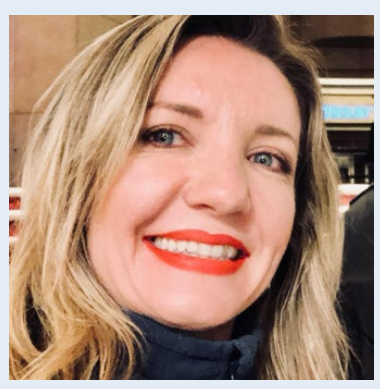

BATTESTIN, V. é professora do Centro de Referência em Formação e em Educação a Distância (Cefor) do InsEtuto Federal do Espírito Santo (IFES). Completou o seu doutorado na Universidade Federal do Espírito Santo (UFES). É líder do grupo de pesquisa Educação e Tecnologia. Seus interesses de pesquisa incluem MOOC, EaD e Tecnologias Educacionais. Foi diretora do Cefor de 2014 a 2019 e desde 2019 é Coordenadora da Universidade Aberta do Brasil no Ifes (UAB).

ORCID: https://orcid.org/0000-0002-4014-1225

CONTATO: +55 27988292885

E-MAIL: vanessa@ifes.edu.br

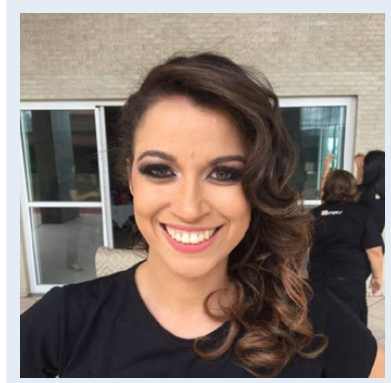

SANTOS, P. S. é mestranta do Centro de Referência em Formação e em Educação a Distância (Cefor) do InsEtuto Federal do Espírito Santo (IFES). Completou sua especialiação na Faculdade Novo Milênio. Seus interesses de pesquisa incluem MOOC, EaD e Tecnologias educacionais. Atualmente é pedagoga e atua como professora na rede municipal de ensino das prefeituras de Vila Velha e Cariacica, no estado do Espírito Santo.

ORCID: https://orcid.org/0000-0002-3314-6271

CONTATO: +55 27 99649-2125

E-MAIL: pollyannadsantos@gmail.com 


\section{Referências}

ABED. Censo EAD.BR 2018: Relatório analítico da aprendizagem a distância no Brasil. 2019. Disponível em: <http://abed.org.br/arquivos/CENSO_DIGITAL_EAD_2018_PORTUGUES.pdf>. Acesso em: 12 abr. 2020.

ANDRADE, M. V. M. Panorama da Aplicação de Massive Open Online Course (MOOC) no Ensino Superior: Desafios e Possibilidades. EaD Em Foco, 6(3). https://doi.org/10.18264/eadf.v6i3.392. Acesso em: 12 abr. 2020.

BATTESTIN, V; SANTOS, P. Modelo ADDIEM - Processo para criação de cursos MOOC. Espírito Santo: Cefor/Ifes, nov. 2019. Disponível em: https://drive.google.com/file/d/1mCWmXBaNFQGOq3laXYmiPxlvDBXE21-s/view. Acesso em: 18 fev.

COSTA, F. et al. Guiões para desenho de cursos mooc. In: Ministério da Educação e Ciênca (Org.). Experiências de Inovação Didática no Ensino Superior. Lisboa, 2015, p. 327-342. Disponível em: <https:// www.researchgate.net/publication/282877714_Guioes_para_desenho_de_cursos_mooc >. Acesso em: 09 ago. 2020.

DAL FORNO, J.; KNOLL, G. F. Os MOOCs no mundo: um levantamento de cursos on-line abertos massivos. Nuances: estudos sobre educação. Presidente Prudente-SP, v. 24, n. 3, p. 178-194, set./dez. 2013. Disponível em: <http://revista.fct.unesp.br/index.php/Nuances/article/view/2705>. Acesso em: 14 abr. 2019.

FASSBINDER, A.; BARBOSA, E.; MAGOULAS, G. Towards an Educational Design Pattern Language for Massive Open Online Courses(MOOCs). HILLSIDE. In:Pattern Languages of Programs Conference.24., 2017, Vancouver. Eletronics Proceedings of the Flop 17. Vancouver: The Hillside Group, 2017. Disponível em: <https://dl.acm.org/doi/pdf/10.5555/3290281.3290283>. Acesso em: 07 ago. 2020.

FILATRO, A. Design instrucional na prática. São Paulo: Pearson Education do Brasil, 2008.

INSTITUTO FEDERAL DE EDUCAÇÃO CIÊNCIA E TECNOLOGIA DO ESPÍRITO SANTO - IFES. COCOMMISSÃO PARA CRIAÇÃO DE CURSOS MOOC DO IFES. Processo e modelos de documentos para cursos abertos MOOC: documento digital. Vitória: Ifes, 2019. Disponível em: https://drive.google.com/drive/folders/1qcXQPIP3WMB3ezEs9cwBf-_G7J__dUmB. Acesso em: 20 abr. 2020.

MATTAR, J. Aprendizagens em ambientes virtuais: teorias, conectivismo e MOOCs. Revista Digital Teccogs, São Paulo, v.18, n.7. p. 20-40, jan-jun. 2013. Disponível em: https://revistas.pucsp.br/teccogs/ article/view/52846/0. Acesso em: 10 jun. 2020.

MURTHY, S. et al LCM: A Model for Planning, Designing and Conducing Learner-Centric MOOCs", 2018, Chennai. Anais da Conferência Internacional sobre Tecnologia para a Educação (T4E), Chennai: Índia, 2018. p. 73-76, doi: 10.1109 / T4E.2018.00022. Acesso em: 09 jun. 2020.

RIBEIRO, L. O. M., CATAPAN, A. H. Plataformas MOOC e Redes de cooperação na EaD. EmRede - Revista De Educação a Distância, 5(1), 45-62. Disponível em: https://www.aunirede.org.br/revista/index.php/ emrede/article/view/297. Acesso em 10 jun 2020.

SCHWARTZMAN, S. Pesquisa acadêmica, pesquisa básica e pesquisa aplicada em duas comunidades cientificas. 1979. Disponível em: http://www.schwartzman.org.br/simon/acad_ap.htm. Acesso em 28 abr 20.

SEIDAMETOVA, Z. Design e Desenvolvimento de MOOCs, 2018, Simferopol. Anais eletrônicos do Workshops ICTERI, Ukraine: CEUR, 2018. Disponível em: http://ceur-ws.org/Vol-2104/paper_244.pdf. Acesso em: 09.out. 2020. 
SIEMENS, G.; FONSECA, D. E. L Conectivismo: Una teoría de aprendizaje para la era digital. Humanas Virtual, 2004. Traducción por LEAL FONSECA, Diego E. (2007). Licenciamiento Creative Commons 2, 5. Disponível em: <http://www.humanasvirtual.edu.ar/wp-content/uploads/2013/12/Siemens2004-Conectivismo.pdf: Acesso em 09 out. 2020.

SOUZA, F.; MORGADO, L.; MARINHO; V. Contribuições para um Framework para Avaliação de Qualidade e Eficácia de MOOCs. Revista Brasileira de Aprendizagem Aberta e a Distância, São Paulo, v. 18, n. 1, p. 1-14, 2019. Disponível em: http://seer.abed.net.br/index.php/RBAAD/article/view/310/292. Acesso em 12 out.2020.

YONG, L; LI, J. (Orgs.). Study on Construction Process of MOOC Course. Eletronics Proceedings of the International Conference on Management, Education and Social Science, 2, 2018, Qingdao, China. Proceedings: Qingdao, China, 2018, p.ICMESS. 